\title{
Baseline Assessment of Oral Health Status of Ashram Schools in Wardha District
}

\author{
Anuja Ikhar ${ }^{1}$, Manoj Chandak ${ }^{2}$, Nidhi Motwani ${ }^{3}$, Akshay Thote ${ }^{3}$, \\ Supriya Sawant ${ }^{3}$
}

Sci. Journal Impact

Factor: $6.1(2018)$

ICV: 90.90 (2018)

\begin{abstract}
'Associate professor, Department of Conservative Dentistry and Endodontics, room no. 103, Sharad Pawar Dental College, Datta Meghe Institute of Medical and Dental Sciences (Deemed to be University), Sawangi, Wardha, Maharashtra 442001, India; 'Professor, Department of Conservative Dentistry and Endodontics, room no. 103, Sharad Pawar Dental College, Datta Meghe Institute of Medical and Dental Sciences (Deemed to be University), Sawangi, Wardha, Maharashtra 442001, India; ${ }^{3}$ Postgraduate student, Department of conservative dentistry and endodontics, room no. 103, Sharad Pawar Dental College, Datta Meghe Institute of Medical and Dental Sciences (Deemed to be University), Sawangi, Wardha, Maharashtra 442001, India.
\end{abstract}

\section{ABSTRACT}

Introduction: Oral health is an essential and vital component of overall health and is associated with much more than just healthy teeth. Ashram schools are one of the initiatives of the government of India for providing education to the children of tribal communities.

Aim: To evaluate the effectiveness of oral health care initiatives in reducing oral morbidities by improving oral health care behaviour amongst ashram school students.

Method: 8 ashram schools were selected for the study. Teachers from 8 Ashram schools attended the one-day Orientation Workshop. A qualitative (semi-structured interview of teachers) and quantitative (survey) method was undertaken for baseline assessment in both the groups. The baseline assessment targeted on detection of dental caries, gingival and periodontal health dietary habits and tobacco chewing habit.

Results: The major weaknesses of Ashram schools were poor training of teachers in detecting health problem and lack of timely treatment of illnesses. Students are from poor and low socio-economic strata of disadvantaged sections of the society. In baseline assessment in the control group, $32 \%$ of students had Caries. In the control group, $57.42 \%$ of students had the presence of the periodontal problem which increases to $63.58 \%$, in the control group, $28.85 \%$ of students had the presence of fluorosis which increases to $33.64 \%$.

Discussion: The oral morbidities during baseline assessment in all the ashram schools was examined. $33.28 \%$ of students have tooth decay, whereas $67 \%$ of students detected with bleeding gums. The fluorosis was found to be in $38.28 \%$ of students and teeth which undergone minor trauma (enamel fracture, dentinal fractures) were seen with $9.14 \%$ students.

Conclusion: This study initiates the thought-provoking response for the dental educators who carry out camps in different setups and indifferent population. The oral morbidities during baseline assessment in all the ashram schools was examined. 33.28 $\%$ of students have tooth decay, whereas $67 \%$ of students detected with bleeding gums. The fluorosis was found to be in $38.28 \%$ of students and teeth which undergone minor trauma (enamel fracture, dentinal fractures) were seen with $9.14 \%$ students.

Conclusion: This study initiates the thought-provoking response for the dental educators who carry out camps in different setups and indifferent population.

Key Words: Ashram School, Oral health, Tribal community, Fluorosis, Tobacco addiction, Dental caries

\section{INTRODUCTION}

Oral health is an essential and vital component of overall health and is associated with much more than just healthy teeth. Difficulties persist, particularly among underprivileged strata, despite sufficient improvement in the overall oral health strat- egy. ${ }^{1}$ The "Ottawa Charter for health promotion" introduced in 1986 in Geneva catered to the Health promotion through "empowering, participatory, holistic, equitable, sustainable, and multi-strategy approach". ${ }^{2}$ The Government of India has also taken an initiative like "tobacco intervention, child dental centre, Oral Cancer Foundation, emergency dental centre,

\section{Corresponding Author:}

Dr. Anuja Ikhar, Associate Professor, Department of Conservative Dentistry and Endodontics, room no. 103, Sharad Pawar Dental College, Datta Meghe Institute of Medical and Dental Sciences (Deemed to be University), Sawangi, Wardha, Maharashtra 442001, India E-mail: anujaikhar@gmail.com

ISSN: 2231-2196 (Print)

Received: 16.06 .2020
ISSN: 0975-5241 (Online)

Revised: 01.08 .2020
Accepted: 23.09 .2020 
healing smiling foundation, National oral cancer registry etc" for the reduction of the grave oral health diseases. These initiatives many times do not reach to the Tribal communities. The most important feature of all the Scheduled Tribe communities in India is that they dwell in tracts of "sloppy land, hills, and forests, having been ousted from the great fertile valleys". They can avail only what is provided by low resource regions which affect adversely their economic conditions. ${ }^{3,4}$

Most of the tribal communities due to their isolation from the society have lack of awareness of the Government promotional programmes and therefore are derived from the benefits of preventive measures specifically related to oral health. Difficulty in obtaining their cooperation in implementing health schemes (Ashram Shala Complex in Maharashtra) due to their low quality of life status and blind beliefs, many times poses a problem in increasing their awareness or providing these benefits. Ashram schools are one of the initiatives of the Government of India for providing education to the children of tribal communities. To increase awareness and also implement preventive measures the best place thus would be to target them at the younger age in these schools. Most of the tribal communities in India are low resource region, where availability of recent advances and basic health care facility is abysmal. Also, they are not aware of various oral health care needs and habits, which make them prone to oral diseases which include, Tooth Decay and Periodontal Problems. By improving their awareness through various Oral Health Care Orientation modules, at the school level, it may help in minimizing the risk of various oral diseases. ${ }^{5,6}$

There are six categories in a school organization. Ashram schools are at the lowest rank. One of the key interventions in educating the Scheduled Tribe children is that of the Ashram schools which have been in tradition for the past years, and have been working in the tribal areas. ${ }^{4}$ Ashram schools are residential schools for scheduled caste, scheduled tribe and nomadic tribe children, whose parents cannot afford schooling for their children. ${ }^{7}$ These schools are residential schools providing all facilities to its inmate and helping them to remain in the school system without dropping out. This is an effort by the government to reach out of the unreached. Most children in tribal areas have poor health and different health needs. ${ }^{8}$ Apart from various diseases, there is a high occurrence of oral health problems among the school children. ${ }^{9,10}$. So the study aimed to evaluate the effectiveness of oral health care initiatives in reducing the oral morbidities by improving the oral health care behaviour amongst ashram school students.

\section{MATERIALS AND METHODS}

After obtaining ethical clearance (IEC Clearance No: DMIMS (DU)/IEC/2015-16/1577- Annexure-1) the 700 children of 5-12 years from Ashram school in Wardha district were selected. The duration of the study was August 2016-August 2017. A total of 8 ashram schools were selected for the study and informed content was obtained from headmaster off school (Annexure-2). Teachers from 8 Ashram schools attended the one-day Orientation Workshop. They have explained the objective and the processes under the study.

Preparatory phase: During this phase, advocacy meetings with the school management, school teachers and parents were carried out to build the rapport.

The purpose of the meeting was conveyed to the attendees of the meeting. The purpose was to obtain on paper informed consent for study from the parents /school teachers of the school. Awareness of dental health among students and its need in the current national context has been discussed in the meeting. The school management was requested to provide demographic data of students to study as an authority. Various committees like Task committee, Reinforcing committee, Monitoring committee, their members and functions were planned. Objectives of the study and methodology needed for the study was thoroughly discussed with the committee members. Parents were made aware of the benefits and risks of the study along with ethical principles.

\section{Baseline assessment}

A qualitative (semi-structured interview of teachers) and quantitative (survey) method was undertaken for baseline assessment in both the groups. The baseline assessment targeted on

- Detection of dental caries using the WHO assessment form, 2013 for children,

- Evaluation of gingival and periodontal health using WHO assessment form, 2013 for children,

- Dietary habits and tobacco chewing habit using WHO questionnaires.

\section{Pre-survey qualitative assessment}

In the qualitative assessment, a semi-structured interview was undertaken with school teachers to explore strengths, weakness, opportunities and challenges in Ashram schools. This exercise was facilitated by a chief investigator during their orientation program.

During school oral health check-up, in-depth interview of school headmaster was undertaken for situation analysis regarding healthy school environment, healthy eating, oral health education, oral injury, oral health services, alcohol and tobacco addiction, oral healthcare-seeking behaviours as per guidelines given in health-promoting schools. This qualitative information was useful for the development of health education materials, needs for future training and intervention strategy. 
Quantitative Assessment (Survey and Measurements)

Eight ashram schools during August 2016 were included in oral health check-up. All children in the school were interviewed and examined by a qualified dentist, dental interns, by using the WHO assessment form, 2013 for children, and WHO questionnaire. Questionnaires on knowledge, attitude, and practice towards oral health from the school teachers were also conducted. The WHO questionnaire 2013 covered information on personal oral hygiene, visit the dentist, reasons for visiting dentist, aids for cleaning teeth, dietary habits, the habit of chewing tobacco, parents occupation and habits, nutrition, and others. The questionnaire was based on the WHO oral health questionnaire for children.

WHO Oral health assessment form for children is recognized as a reliable method for primary and permanent dentition status and periodontal status. Enamel fluorosis, dental erosion, dental trauma, was also examined using the WHO Oral health assessment form for children. A session was conducted on the importance of deciduous teeth, dietary habits, and first aid treatment protocol for the teachers. Oral Health education sessions were conducted by using oral health education material developed at Sharad Pawar Dental College, Sawangi Wardha, Maharashtra.

\section{Statistical analysis}

Proportions were expressed for oral health conditions and behaviours along with their $95 \%$ Confidence Interval. Absolute and relative effect measures were reported along with their $95 \%$ Confidence Interval. Content analysis of qualitative data was done. The software used in the analysis was SPSS 22.0 and Graph Pad Prism 5.0 version and $\mathrm{p}<0.05$ is considered as the level of significance. The statistical tests used for the analysis of the result was the Chi-square test

\section{RESULTS}

\section{Findings from the qualitative assessment}

\section{SWOC analysis}

Strengths: building (infrastructure), accessibility of power supply, safe drinking water, trained teaching staff and playground.

Weaknesses: poor training of teachers in detecting health problem and lack of timely treatment of illnesses. Students are from poor and low socio-economic strata of disadvantaged sections of the society. Most of them have faith in supernatural causation of diseases and black magic. Addiction to tobacco products among school children is common practice.

Opportunities: Teachers willingness to participate in this new project and scope for improving the health of school children.
Concern: Poor support from parents, school children and their deep-rooted belief in supernatural causation of diseases and black magic.

Parent-teacher association: Out of 8 schools only 5 schools arranged annual meetings with parents. The parents of most of the children are poor, illiterate daily wedge labourers. Hence, they do not recognize the importance of education and hygienic practices. Children are taken home for local festivals like Ganeshotsav, Pola, Holi and Diwali and often become late in joining back the school. The reason told was that the parents are poor and had to wait for some time to arrange money for the back journey. Hence the thought of parent-teacher union and their regular assembly could be seen as a challenge.

Eating habits: All the schools have a separate kitchen. It was observed that Regular meals are prepared and served to ashram schools children. Hand washing tradition was unfortunate as hands were washed with water only. It was found most ashram school children were habitual to unhealthy and harmful food eating habits (toffees, sugary candies). Nutritious food like milk, eggs, leafy vegetables etc. was not served to the students in most of the school.

Awareness of oral health education and behaviour: questionnaire survey has been conducted on knowledge, attitude and behaviour regarding oral health. Teachers of the ashram schools were the respondents. Residential teachers were also asked about the brushing and tobacco chewing habits of the children. Teachers were asked about the knowledge regarding first aid provided to the children in case of oral trauma.

\section{Findings of Baseline Assessment}

The oral morbidities during baseline assessment in all the ashram schools were examined. $33.28 \%$ of students have tooth decay, whereas $67 \%$ of students detected with bleeding gums. The fluorosis was found to be in $38.28 \%$ of students and teeth which undergone minor trauma (enamel fracture, dentinal fractures) were seen with $9.14 \%$ of students. Data shown in following Tables 1 to 5 .

Table 1: Ashram schools covered and number of children examined

\begin{tabular}{llc} 
Sr. No & $\begin{array}{l}\text { Name of Ashram } \\
\text { Schools }\end{array}$ & $\begin{array}{c}\text { Number of Students in } \\
\text { Baseline Assessment }\end{array}$ \\
\hline 1. & Dahegaon & 104 \\
2. & Hirapur & 72 \\
3. & Nimboli & 146 \\
4. & Wadgaon Junglee & 28 \\
5. & Kolhapur & 99 \\
6. & Nara & 59 \\
7. & Waigaon Gond & 90 \\
8. & WaigaonNipani & 102 \\
& TOTAL & 700 \\
\hline
\end{tabular}


Table 2: Baseline demographic data of students in all ashram schools Demographic Students in ashram schools

\begin{tabular}{llr} 
Sex & Male & 327 \\
& Female & 373 \\
Total & & 700 \\
\hline
\end{tabular}

Table 3: Baseline finding of Dietary habits patterns of the students based on the WHO questionnaire

\begin{tabular}{|c|c|c|c|c|c|c|}
\hline $\begin{array}{l}\text { Type and nature of } \\
\text { diet }\end{array}$ & $\begin{array}{l}\text { Many times in } \\
\text { a day }\end{array}$ & Daily & $\begin{array}{l}\text { Many times in } \\
\text { a week }\end{array}$ & Weekly once & $\begin{array}{l}\text { Many times in the } \\
\text { month }\end{array}$ & Never \\
\hline Fresh fruits & - & $\begin{array}{c}170 \\
(24.28 \%)\end{array}$ & - & $\begin{array}{c}236 \\
(33.71 \%)\end{array}$ & $\begin{array}{c}116 \\
(16.57 \%)\end{array}$ & $\begin{array}{c}178 \\
(25 \cdot 42 \%)\end{array}$ \\
\hline Biscuits, bread & & $\begin{array}{c}208 \\
(29.71 \%)\end{array}$ & $\begin{array}{c}251 \\
(35.85 \%)\end{array}$ & $56(8 \%)$ & $\begin{array}{c}107 \\
(15.78 \%)\end{array}$ & $\begin{array}{c}72 \\
(10.28 \%)\end{array}$ \\
\hline Cold drink & & & & & & $\begin{array}{c}700 \\
(100 \%)\end{array}$ \\
\hline Honey & & & & & $\begin{array}{c}193 \\
(27.57 \%)\end{array}$ & $\begin{array}{c}507 \\
(72.42 \%)\end{array}$ \\
\hline Sweets & $\begin{array}{c}218 \\
(31.14 \%)\end{array}$ & $\begin{array}{c}128 \\
(18.28 \%)\end{array}$ & & $4(0.57 \%)$ & & $\begin{array}{c}350 \\
(50 \%)\end{array}$ \\
\hline $\begin{array}{l}\text { Sugary candies } \\
\text { /toffees }\end{array}$ & & $\begin{array}{c}271 \\
(38.71 \%)\end{array}$ & $\begin{array}{c}261 \\
(37.58 \%)\end{array}$ & $\begin{array}{c}96 \\
(13.71 \%\end{array}$ & & $\begin{array}{c}72 \\
(10.28 \%)\end{array}$ \\
\hline Milk & & $\begin{array}{c}252 \\
(36 \%)\end{array}$ & $\begin{array}{c}248 \\
(35.42 \%)\end{array}$ & $\begin{array}{c}17 \\
(2.42 \%)\end{array}$ & $\begin{array}{c}101 \\
(14.42 \%)\end{array}$ & $\begin{array}{c}83 \\
(11.87 \%)\end{array}$ \\
\hline Tea & & $\begin{array}{c}576 \\
(82.28 \%)\end{array}$ & $\begin{array}{c}72 \\
(10.28 \%)\end{array}$ & & & \\
\hline Coffee & & & & & & $\begin{array}{c}700 \\
(100 \%)\end{array}$ \\
\hline
\end{tabular}

Table 4: Baseline data based on the WHO questionnaire for Addiction to tobacco

\section{Consumption of tobacco during baseline}

Girls

293

$(78 \%)$

75

$(20 \%)$

36

$(9.65 \%)$

56

$(15.01 \%)$

\section{Boys}

227

$(69.41 \%)$

255

$(77 \cdot 98 \%)$

220

$(67.27 \%)$

235

$(71.86 \%)$

${ }^{*}$ Kharra- It is smokeless tobacco consisting of a combination of tobacco, areca nut, lime, catechu, with additional ingredients. It is usually held in the mouth and chewed.

${ }^{* *}$ Gutkha- It is smokeless tobacco consisting of tobacco, crushed areca, spices

Table 5: Baseline data for the dentition status, periodontal status, fluorosis status and trauma

$\begin{array}{lcc}\text { Morbidities } & \text { Presence } & \text { Absence } \\ \text { Caries } & 233(33.28 \%) & 467(66.71 \%) \\ \text { Bleeding gums } & 469(67 \%) & 231(33 \%) \\ \text { Fluorosis } & 268(38.28 \%) & 432(61.71 \%) \\ \text { Trauma } & 64(9.14 \%) & 636(90.85 \%)\end{array}$


The dietary habits of all the ashram schools students during baseline assessment were examined. $38.71 \%$ of students daily consumed sugary candies /to fees while $37.58 \%$ consumed it many a time in the week. The addiction of tobacco and related product consumed of all the ashram school students during baseline assessment. $78 \%$ of girls and $69.41 \%$ of boys have a habit of brushing teeth with Nus .whereas $20 \%$ girls and $77.98 \%$ of boys consumed Kharra. $9.65 \%$ of girls and $67.27 \%$ of boys consumed Gutkha. $15.01 \%$ of girls and $71.86 \%$ of boys have a habit of chewing dry tobacco (Table 4 and Table 5).

\section{DISCUSSION}

The study was carried out in ashram schools. The biggest problem is the lack of capacity building and training of teachers helping in the Ashram schools in general of all the states. There were no provision of training and orienting the teachers and head of ashram school under Education Departments of various states. The tribal development departments have not formed such structure and services. ${ }^{4,9}$

The main cause for this is the insufficient education in tribal areas because of their remoteness; tribal hamlet being left out from main villages or rural areas; the difficulty encountered by children existing in smaller habitations in accessing obtainable official schools; and so on. The other reason for modest enrolment in school among children of Scheduled Tribe includes the unwillingness of families to teach their children. Eight Ashram schools in central India region were selected for the present study. After obtaining the written permission from the school headmaster for this project, a one day workshop was conducted in schools to explain the objectives and process of the study in details. Oral health problems are preventable and their early commencement irreversible, however huge number of children, their parents and teachers have limited information about oral diseases. ${ }^{11}$ Awareness of dental health among students and its need in the current national context has been discussed thoroughly in the meeting.

All the teachers were aware of the possible causes of tooth decay. $91 \%$ of teachers knew that oral health is important and is correlated with the general health and wellbeing of an individual. Participants were aware that improper brushing will lead to decay, bad breath, gum diseases as well as stains. Teachers of this study showed more knowledge of the effects of irregular brushing when compared with the studies done by Khan et al. ${ }^{12}$

The survey was also conducted to check the magnitude of oral health condition and oral hygiene practice in ashram school. The registration of oral diseases was based on WHO oral assessment 2013 for the children. The WHO oral assessment form is a standardized measurement of oral diseases and circumstances that are main for the development and assessment of the oral health programme, as well as compatibility of data taken in a different environment. The main aim of this assessment form is to support regular reporting of data on oral conditions; also make sure that data collected are dependable within. ${ }^{13}$

The collection of qualitative information is undertaken using a pre-structured interview based on "five areas of health promotion "identified in the Ottawa Charter. Within a past, present and future frame, each of these areas were accessed relating to the promotion of oral health in ashram school. A SWOC analysis "Strengths, Weaknesses, Opportunities, and Concerns" was incorporated in the last part of each interview for the conclusion of main points.

During baseline assessment, a total of 700 students was included, out of which 327 were male and 373 were female.

The result of this study is in congruence with work carried out by Gunjal Sandeep S, Borle Amod L. ${ }^{14}$ In their study smokers among boys were $4.10 \%$ as compared to $1.57 \%$ girls. Although the share is greater amongst boys, girls of tribal areas succumb to the practice of smoking at this age itself is a subject of concern (Table 1). The result of this study is in congruence with work carried out previously. ${ }^{15}$ Occurrence of various forms of smokeless and smoking tobacco use in tribal adolescents were $54.45 \%$, and $23.14 \%$, respectively. Incidence of use of tobacco in boys $(66.25 \%)$ was greater than girls $(26 \%)$. In the late adolescent period and adolescents in earning period, the frequency of tobacco use was more. The common age of initiating smokeless tobacco and smoking was 13.75 years and 14.22 years respectively. Boys begin smoking somewhat firmer than girls $(\mathrm{P}=0.04)($ Table 2 and 3).

Dental injuries could have improved outcomes if the school's teachers were aware of first-aid measures and the need to seek immediate treatment. In the control group, $9.71 \%$ of students had a presence of trauma in a baseline assessment. A study conducted by Utkarsha Basakhetre ${ }^{16,17}$ maximum users $(2.3 \%)$ were 15 years of age and $(2.1 \%)$ were 14 years of age followed by 13 and 16, respectively. Sugar intake betweenmeal was high $(100 \%) .{ }^{18}$ Neither of the children in both the age groups had a visit to qualified health personnel for dental management. Prevalence of dental fluorosis in 5- and 12year olds was $11.9 \%$ and $22.9 \%$ respectively. In both the age groups bleeding on probing and calculus was frequent. For 5- and 12-year old, mean dmft/DMFT values were $4.13 \pm$ 3.90 and $1.15 \pm 1.62$. For 5 - and 12-year olds, significant caries index (SIC) scores were $7.17 \pm 4.30$ and $3.78 \pm 3.21$ respectively. They concluded that there was a high incidence of dental fluorosis, high sugar intake, poor oral hygiene, and untreated dental ailment of tribal children. Under these conditions, the execution of preventive program included control of sweets in the school building for the tribal children is 
the solution to superior oral health which was in correspondence with this study.

\section{CONCLUSION}

This study initiates the thought-provoking response for the dental educators who carry out camps in different setups and indifferent population. They need to initiate more dental awareness program for parents and their children at the preschool set up to assess as well as to spread the oral health awareness in Indian society. Efforts should be made to involve all teachers to educate and teach the child. Evaluation of community oral disease prevention and oral health promotion programmes should integrate with a general evaluation of health programme.

\section{ACKNOWLEDGEMENT}

Authors acknowledge the immense help received from the scholars whose articles are cited and included in references to this manuscript. The authors are also grateful to authors/ editors/publishers of all those articles, journals and books from where the literature for this article has been reviewed and discussed.

\section{Conflict of Interest: Nil}

\section{Source of Funding: Nil}

\section{REFERENCES}

1. Singh A. Oral health policies in developing countries. J Public Health Policy 2010 Dec;31(4):498-9.

2. World Health Organization: Ottawa Charter for Health Promotion. Geneva: World Health Organization. The Ottawa Charter for Health Promotion, First International Conference on Health Promotion, Ottawa, November 1986.

3. Panda BK. Development of the Scheduled Tribes - A Perspective (Mimeo). NUEPA, New Delhi 2008.

4. Panda BK. Understanding multiple disadvantages for inclusive educational development of scheduled tribe children. All India Asso Edu Res 2013;31:212.
5. World Health Organization: Health promotion evaluation: Recommendations to pol icy makers. Copenhagen: World Health Organization Regional Office for Europe. 1998.

6. Petersen PE, Peng B. Effect of a school-based oral health education programme in Wuhan City, People's Republic of China. Int Dent J 2004;54(1):33-41.

7. Panda BK. Organization and functioning of schools in the tribal areas. Pariprekshya 2000; 7(4):18-29.

8. Gondivkar SM, Bhowate RR, Gadbail AR, Sarode SC, Gondivkar RS. Assessment of oral health-related quality of life instruments for oral submucous fibrosis: A systematic review using the COnsensus-based Standards for the selection of health Measurement Instruments (COSMIN) checklist. Oral Oncology 2019;93:39-45

9. Patel S. Tribal Education in India. Mittal Publication, New Delhi. 1991 1stEd.

10. Sujatha K. An In-depth Study of Ashram schools in Andhra Pradesh (Mimeo). NIEPA, 1983.

11. Wierzbicka M, Petersen PE, Szatko F, Dybizbanska E, Kalo I. The effect of Changing oral health status and oralhealth behaviour of schoolchildren in Poland. Commu Dent Health 2002 Dec;19(4):243-50.

12. Khan N, Al-Zarea B, Al-Mansour M. Dental caries, hygiene, fluorosis and oral health knowledge of primary school teachers of Riyadh, Saudi Arabia. Saudi Dent J 2001;13(3): 128-132.

13. Oral health survey manual, Basic methods, WHO, Geneva, 2008;5 th. Edition

14. Gunjal S. Tobacco and Alcohol Use in Tribal School students from Central India. International Journal of Collaborative Research on Int. Med. Public Health. 2012; 4(11).

15. Zahiruddin QS, Gaidhane A, Bawankule S, Nazli K, Zodpey S. Prevalence and pattern of tobacco use among tribal adolescents: Are tobacco prevention messages reaching the tribal people in India. Ann Trop Med Public Health 2011;4(2):74.

16. Basakhetre U, Jaiswal A, Deolia S, Sen S, Dawngliani M, Jaiswal A. Prevelance of tobacco use among school children reporting to dental hospital for treatment. J Datta Meghe Inst Med Sci Univ 2017 Oct 1;12(4):242.

17. Gondivkar SM, Bhowate RR, Gadbail AR, Gondivkar RS, Sarode SC, Sarode GS, Patil S. Impact of oral submucous fibrosis on oral health-related quality of life: A condition-specific OHRQ oL-OSF instrument analysis. Oral Dis 2018 Nov;24(8):1442-8.

18. Singh A, Bharathi MP, Sequeira P, Acharya S, Bhat M. Oral health status and practices of 5 and 12-year-old Indian tribal children. J Clin Pediatr Dent 2011;35(3):325-30. 